Original Research Paper

\title{
Parametric Study to Maximize the Useful Life of Reinforced Concrete Columns
}

\author{
Tamires L. Mezzomo and Moacir Kripka \\ Department of Civil Engineering, University of Passo Fundo, Passo Fundo, Brazil
}

\author{
Article history \\ Received: 06-04-2021 \\ Revised: 24-04-2021 \\ Accepted: 09-05-2021 \\ Corresponding Author: \\ Moacir Kripka \\ Department of Civil \\ Engineering, University of \\ Passo Fundo, Passo Fundo, \\ Brazil \\ Email: mkripka@upf.br
}

\begin{abstract}
The current scenario of structural engineering is guided by the growing ecological concern and constant search for efficient and economic structural solutions. In this sense, aspects related to the durability of structures have become a significant topic of study. Based on this context, the purpose of this work was to provide resources that allow the maximization of the useful life of reinforced concrete columns during the design phase. To achieve this objective, different scenarios were simulated for the properties of concrete and environmental properties and the corresponding transversal cross-sections were defined with the usage of an optimization method. The results obtained showed that the parameters that most interfere in the durability of the structure are the covering thickness and the compression strength. It was found that the durability increases significantly when the concrete strength increases and similar behavior was observed when the thickness of the covering is increased. Regarding optimization, it was noted that to higher compressive strengths of concrete the cost of the column section is reduced. The results of the developed study provided subsidies for maximizing the useful life of reinforced concrete columns in the design phase. Supported by the study, it was also observed the high sensitivity of the useful life to changes in coverage and properties of concrete. It was also concluded that the increase in compressive strength not only increases durability but also has the propensity to reduce the cost of the structure.
\end{abstract}

Keywords: Carbonation, Covering, Reinforced Concrete, Durability,

Useful Life

\section{Introduction}

The reinforced concrete construction system is widely used worldwide. Therefore, the search for more effective solutions, with low cost and higher durability, must be a priority in engineering projects. Currently, the limited availability of resources, the need for more sustainable buildings and the number of reinforced concrete constructions with pathological manifestations make studies on durability increasingly important (Gardner et al., 2018). In reinforced concrete structures the most common pathology is corrosion (Bueno et al., 2019). It can be detected mainly through surface stains and cracks, degradations that compromise structural safety. Besides, infrastructures and buildings that operate longer with high performance have a positive impact on the environment (Van Mullem et al., 2020).

Among the various factors that influence deterioration due to carbonation, the water/cement ratio, the thickness of the covering, the type of cement and the curing process can be highlighted (Rao and Meena, 2017). Given the uncertainties related to these factors, the determination of the useful life in reinforced concrete structures submitted to the carbonation effect can be only established by probabilistic means. Technical standards, such as the Brazilian ABNT NBR 6118:2014, in the scope of durability, present indications relating the class of environmental aggressiveness with the covering thickness. However, for the probabilistic treatment to be incorporated into the technical standards, some further improvements are still needed.

Considering that the reduction of the cost and the increase of the useful life are conflicting objectives, this work presents a study seeking to identify parameters that maximize the useful life in reinforced concrete columns in the design phase without significantly increasing its cost. In this study, the model 
proposed by the Spanish Concrete Standard was used for the probabilistic prediction of the useful life of the columns. Different scenarios were simulated for the properties of the concrete and environmental properties and the corresponding transversal cross-sections were defined with the usage of an optimization method.

This paper is structured as follows: In the second section, the factors that can influence the useful life of reinforced concrete structures are described, as well as the form of their determination; the third section describes the methodology used in the study to evaluate the relative importance of these factors; the fourth section presents results obtained from the implementation of the formulation; finally, the resulting conclusions are listed in the fifth section.

\section{Useful Life of Reinforced Concrete Structures}

\section{Factors that Influence the Carbonation Process}

During the concrete curing process and on adequate humidity conditions, a pore network is formed and filled with a solution that provides concrete with high alkalinity ( $\mathrm{pH}$ ranging from 12.6 to 13.5). In presence of oxygen, it creates a very adherent oxide layer that protects the steel from corrosion. This layer is called the passive layer (Possan et al., 2016). By reducing the alkalinity of the concrete, carbonation alters the conditions of chemical stability of passive reinforcement, thus generating a favorable environment for the occurrence of corrosion. The process takes place from the concrete surface to its interior and is called carbonation front.

Several properties of the material and structure directly influence the progress of carbonation, including:

\section{Water/Cement Ratio (w/c)}

The w/c ratio is an extremely important parameter for determining the carbonation depth since it determines the porosity and permeability characteristics of the concrete that gives protection to the reinforcement. The higher the $\mathrm{w} / \mathrm{c}$ ratio, the greater the porosity and, as a result, the greater the diffusion speed (Cao et al., 2020).

\section{Covering}

The covering layer has a protective function regarding the reinforcement. This protection can be of physical or chemical nature. A reinforcement cover made of high-quality concrete, without voids and low w/c content guarantees protection against the attack of aggressive external agents.

\section{Cement and Additions}

Several studies have been carried out to investigate the influence of the type of cement on the durability of the concrete (Joukoski et al., 2004; Alexander and
Beushausen, 2019). Concretes that contain blast furnace slag or additions of pozzolanic materials in their composition have less porosity and, therefore, greater resistance to the penetration of liquids, gases and ions. However, there is no consensus about the positive or negative contribution of additions to carbonation (Santos et al., 2020).

\section{Healing and Densification}

The curing of the concrete is the time necessary for the initial reactions of hydration and hardening of the cement. It is directly dependent on the humidity and temperature of the place at the time of concreting. It is extremely important to guarantee enough water for hydration reactions, to allow good final quality to the concrete. A bad cure produces a high porosity mainly on the external surface, allowing the penetration of agents that increase the depth of carbonation (Kim et al., 2020).

\section{Cracking}

The superficial cracking of the concrete substantially increases the permeability, decreasing the protection of the reinforcement against the entry of aggressive agents. Carbonation occurs along the crack, accelerating the decrease in the $\mathrm{pH}$.

\section{Compressive Strength of Concrete}

The compressive strength of concrete is directly linked to the porosity of concrete. The stronger it is, the smaller the number of pores, therefore influencing the carbonation depth (Possan et al., 2016).

\section{Environmental Conditions}

The carbonation speed and durability of the structure are also directly associated to the aggressiveness of the environment and the relative humidity of the place where the structure is located. The more aggressive the environment, with a high concentration of $\mathrm{CO}_{2}$ in the atmosphere, the more carbonation speed increases, allowing $\mathrm{CO}_{2}$ to reach the reinforcement (Possan et al., 2016).

\section{Lifetime Prediction Model}

Among the various models for predicting the useful life of reinforced concrete structures, in the present work the model proposed by the Spanish Concrete Standard (Fomento, 2008) was adopted. To present the mechanism of corrosion of steel in concrete, the model was proposed based on the studies and proposals of Tutti (1982), according to which the corrosive process is divided into two phases, being: Initiation and propagation. The first is the beginning of corrosion, in which carbonation penetrates the concrete layer and starts the process of depassivation. This phase can be modeled according to Eq. 1: 


$$
d=k \sqrt{t}
$$

Where:

$d$ : Depth of penetration of the aggressive agent, in $\mathrm{mm}$

$k$ : Coefficient of carbonation (varies according to the characteristics of the material)

$t$ : Time, in years

Thus, the time for carbonation to penetrate the covering layer and reach the reinforcement can be estimated from Eq. 2 as:

$$
t=\left(d / k_{c}\right)^{2}
$$

where the variables $d$ and $t$ have the same definitions as in Eq. 1. The variable $k_{c}$ refers to the carbonation factor and can be determined by Eq. 3:

$$
k_{c}=C_{e n v} * C_{a i r} * a * f_{c m}^{b}
$$

Where:

$f_{c m}$ : Compressive strength of concrete, in $\mathrm{N} / \mathrm{mm}^{2}$

$C_{e n v}$ : Environmental factor

$C_{\text {air }}$ : Aeration factor of concrete

$a, b$ : Parameters related to the type of cement

The second phase involves the spread of corrosion and extends to reach an unacceptable limit. The time required to reach this limit is determined by Eq. 4:

$$
t p=\frac{80 * d}{\varnothing * v_{\text {corr }}}
$$

\section{Being:}

$t p$ : Propagation time, in years

$d$ : Thickness of the covering, in $\mathrm{mm}$

Ø: $\quad$ Rebar diameter, in $\mathrm{mm}$

$v_{\text {corr }}$ : Corrosion rate, in $\mu \mathrm{m} /$ years

The useful life is therefore calculated as the sum of the two phases, as in Eq. 5:

$t=\left(\frac{d}{k}\right)^{2}+\frac{80 * d}{\varnothing * v_{\text {corr }}}$

\section{Methodology}

To assess the influence of the listed parameters on the increase in the service life of reinforced concrete columns, the present research design, done through the mixed-method (quantitative and qualitative), was divided in two phases. In the first, column sections were optimized for different strengths, covers and types of cement. In the second phase, the useful life of the optimized columns was determined.

\section{Section Optimization Units}

\section{Formulation and Implementation of the Problem}

An optimization problem consists of finding the values of a set of design variables, according to given constraints, to minimize or maximize an objective function (Dede et al., 2019). In the present study, the optimization of the cross-sections of reinforced concrete columns submitted to uniaxial flexural compression was carried out by adapting the formulation originally developed by Bordignon and Kripka (2012). In this, the objective is to minimize the total cost of steel, concrete and formwork, taking as variables the dimensions of the concrete section and the number of bars with their corresponding diameters. The constraints are related to the section's strength capacity as well as to constructive aspects such as the reinforcement ratio and the spacing between bars. The same formulation was adapted by de Medeiros and Kripka (2014) to include the minimization of environmental impact as an objective.

The formulation was implemented by the usage of Simulated Annealing optimization method. Simulated Annealing consists of a heuristic optimization method, developed by Kirkpatrick et al. (1983) in analogy to the process of annealing of metals. Briefly, the process consists of heating the metal to high temperatures causing the atoms to move freely. Soon after, solidification takes place through slow and controlled cooling, thus forming a uniform structure with minimal energy. The algorithm, therefore, seeks the temperature that generates the least energy when solidifying the metal. From an initial temperature and energy, a next state is generated where the temperature is varied. If the new solution is better than the previous one, it becomes the new current solution. Otherwise, the acceptance will be made by a probabilistic criterion (Metropolis criterion). The procedure is finalized when the temperature is close to zero and no solution worsens the value of the accepted solution, representing a stable system.

\section{Valued Parameters}

For the simulations, some parameters were considered fixed in the optimization process. Initially, the characteristic strength of the concrete (fck) was limited to values between 20 and $45 \mathrm{MPa}$ and varying every $5 \mathrm{MPa}$. Another input parameter set was the reinforcement cover. For this, values of 25, 30, 40 and $50 \mathrm{~mm}$ were adopted. These input data were combined, so that for each strength value, each of the four cover thicknesses is associated.

The adopted stresses were obtained from Bordignon and Kripka (2012) taking as axial stress Nsd $=2,480 \mathrm{KN}$ and bending moment Msd = 324,89 KN.m. 
Table 1: Unit cost of materials

\begin{tabular}{lll}
\hline $\mathrm{Cc}\left(\mathrm{R} \$ / \mathrm{m}^{3}\right)$ & $20 \mathrm{MPa}$ & 339.71 \\
& $25 \mathrm{MPa}$ & 354.94 \\
& $30 \mathrm{MPa}$ & 368.96 \\
& $35 \mathrm{MPa}$ & 397.37 \\
& $40 \mathrm{MPa}$ & 427.54 \\
& $45 \mathrm{MPa}$ & 453.55 \\
$\mathrm{Cs}(\mathrm{R} \$ / \mathrm{Kg})$ & 9.00 & \\
$\mathrm{Cf}\left(\mathrm{R} \$ / \mathrm{m}^{2}\right)$ & 82.31 & \\
\hline
\end{tabular}

Each new model was run in the software five times, being adopted the best solution. The computer used for optimization has an Intel Core i7-8550U processor, 8GB RAM and 64-bits operating system.

The unit cost referring to form (Cf), reinforcement (Cs) and concrete $(\mathrm{Cc})$ include materials, labor and equipment and are listed in Table 1, in Brazilian Currency Reais (R\$).

\section{Determination of Useful Life}

For the calculation of Useful Life (UL) of columns according to Eq. 1 to 5, the parameters of fck and cover adopted were the same used for the optimization of the section under study. Regarding the reinforcement diameter, the value adopted was the highest among those obtained in the optimization process if more than one diameter results from the optimization. As for the type of cement, Portland CPII was adopted, with additions of blast furnace slag (CII-E). The structure was considered to be protected from rain, with less than $4.5 \%$ of concrete aeration. The aggressiveness class considered medium and high humidity.

\section{Numerical Simulations and Analysis of Results}

\section{Influence of Coverage on Durability and Costs}

To the considered concrete strengths, Fig. 1 presents the influence of the covering on the useful life of reinforced concrete columns.

When analyzing the results to $20 \mathrm{MPa}$, for average humidity, it can be seen an increase of $29 \%$ on average in durability to each $10 \mathrm{~mm}$ of increase in coverage. For example, for the same strength, the increase in useful life between the 25 and $50 \mathrm{~mm}$ coverings presents a variation of $115 \%$. If the durability is analyzed, for the same covering and increasing the concrete strength by $5 \mathrm{MPa}$ (from 25 to $45 \mathrm{MPa}$ ), it can be observed a progressive increase of 24 , $26,28,30$ and $31 \%$, respectively.

By analyzing the cover, from a global average among all strengths, an average increase of $14 \%$ in the UL is determined to every $10 \mathrm{~mm}$ added to the covering. The relation of durability of the column and the covering thickness can be clearly verified, once the covering layer acts as a protection for the reinforcement and, as a consequence, reduces the speed of the corrosive process.

The columns subjected to high humidity behave in the same way as those previously analyzed, as observed in Fig. 2.

From Fig. 2 it can be noticed that an increasing in the covering increases the useful life significantly. For an addition of $10 \mathrm{~mm}$ in coverage to a fixed strength, an average increase of $41 \%$ on durability can be observed. If the results are compared to those obtained for average humidity, a difference of $27 \%$ is found, making evident that for average humidity the covering is important, but not as important as in columns with high humidity incidence.

Analyzing the variation in costs, it was clearly observed from Fig. 3 the decrease in the costs of the sections by increasing the strength of the concrete, despite that the unit cost of concrete also increases with strength.

By comparing the results of costs and coverage, it is noted that by varying the coverage, the useful life is increased and, at the same time, the costs of the section are not changed significantly.

\section{Influence of the Variation of the Strength of the Concrete on the Durability and Costs of the Section}

The useful life results generated for each strength value, considering an average humidity and different covering values are presented in Fig. 4. When compared to those results presented in Fig. 3, it can be concluded that when using higher concrete strengths, besides the maximizations of useful life, the costs are significantly reduced.

Also, through Fig. 4 the great influence of concrete strength on durability can be observed. For example, when compared a concrete column of $45 \mathrm{MPa}$ and cover of $50 \mathrm{~mm}$ with a column of the same cover and $20 \mathrm{MPa}$, there is a $67 \%$ decrease in durability and a cost reduction of $32 \%$. Considering concretes of 40 and $45 \mathrm{MPa}$ with a coverage of $50 \mathrm{~mm}$, an increasing $46 \%$ on useful life can be achieved. In general, to each $5 \mathrm{MPa}$ added to the strength and maintaining the same coverage, durability is increased approximately by $38 \%$, while costs are reduced by $6 \%$ on average.

The results generated from the study of structures subjected to high humidity followed the same pattern as the results obtained to average humidity, as seen in Fig. 5.

When analyzing the increase in UL to $45 \mathrm{MPa}$ concrete section and $50 \mathrm{~mm}$ coverage, from medium to high humidity and compared to a concrete section of 30 $\mathrm{MPa}$ and the same coverage, there is a $54 \%$ decrease in UL. Thus, it can be emphasized again that the compressive strength of the concrete is of great importance in durability. 
Tamires L. Mezzomo and Moacir Kripka / International Journal of Structural Glass and Advanced Materials Research 2021, Volume 5: 226.233 DOI: 10.3844/sgamrsp.2021.226.233

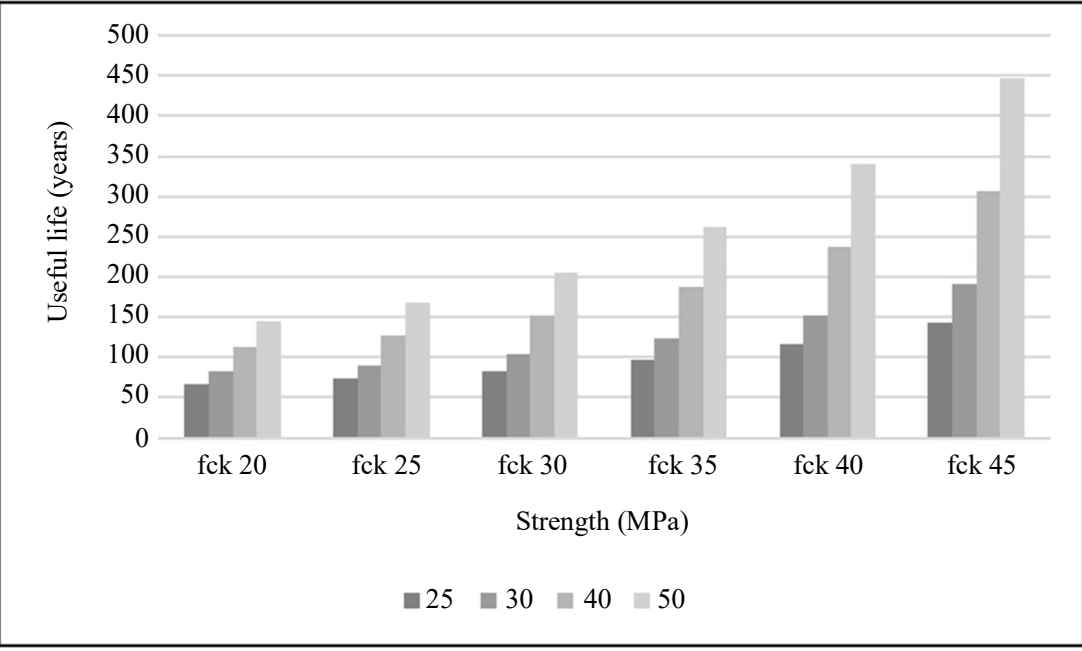

Fig. 1: Influence of cover on Useful Life (UL) - average humidity (covering in mm)

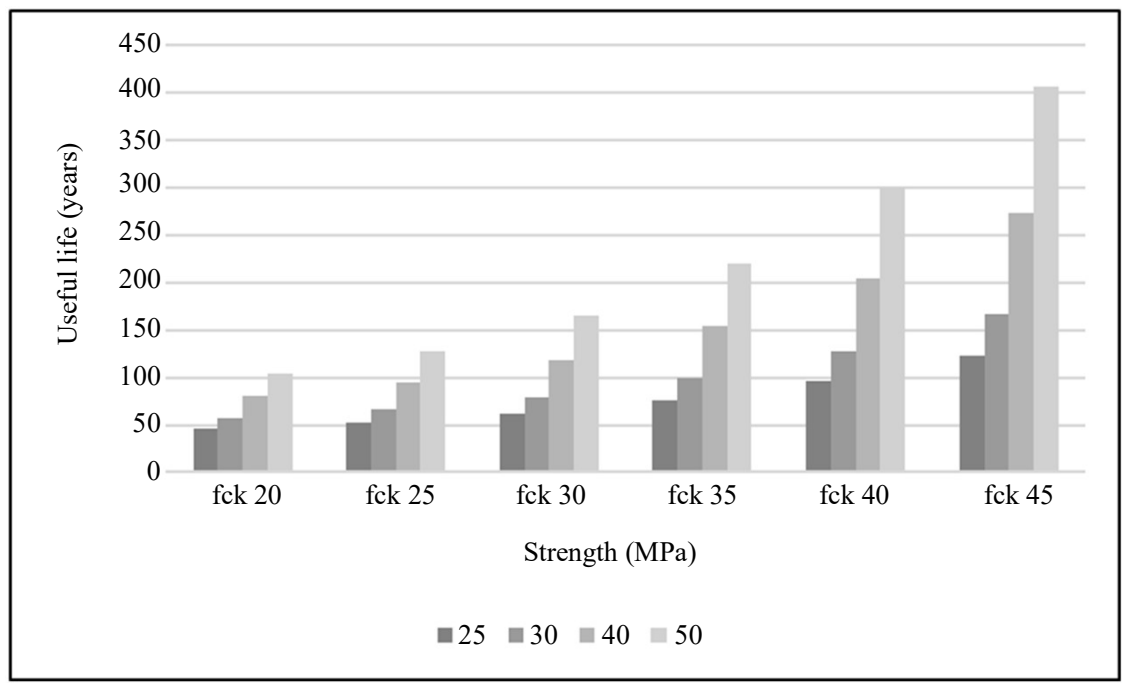

Fig. 2: Influence of coverage on UL - high humidity (covering in $\mathrm{mm}$ )

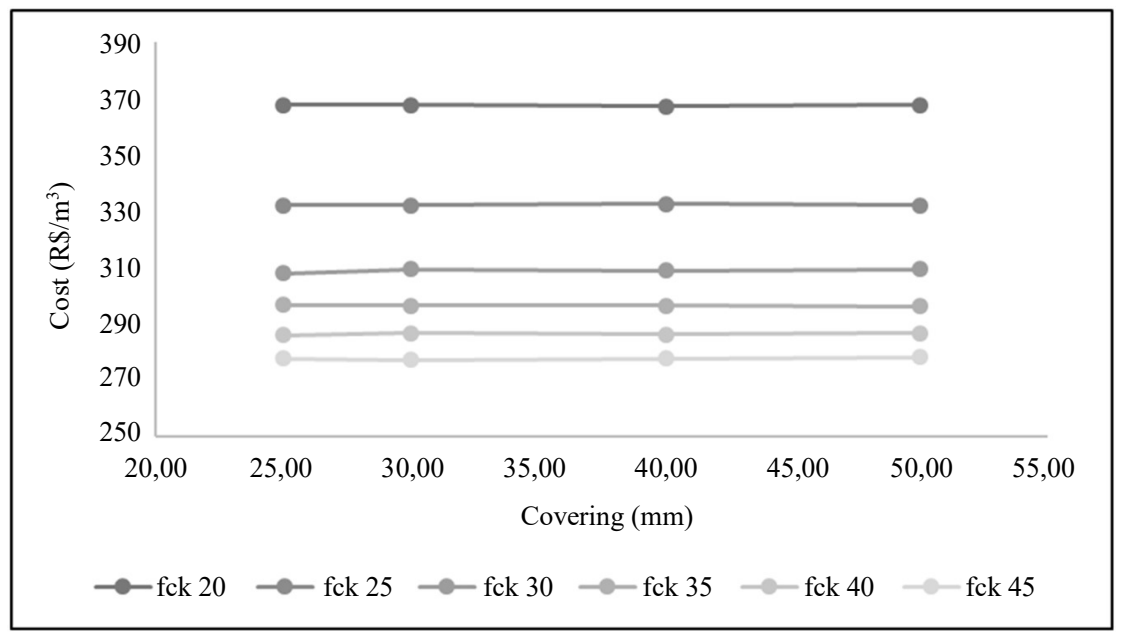

Fig. 3: Cost variation for different strengths 


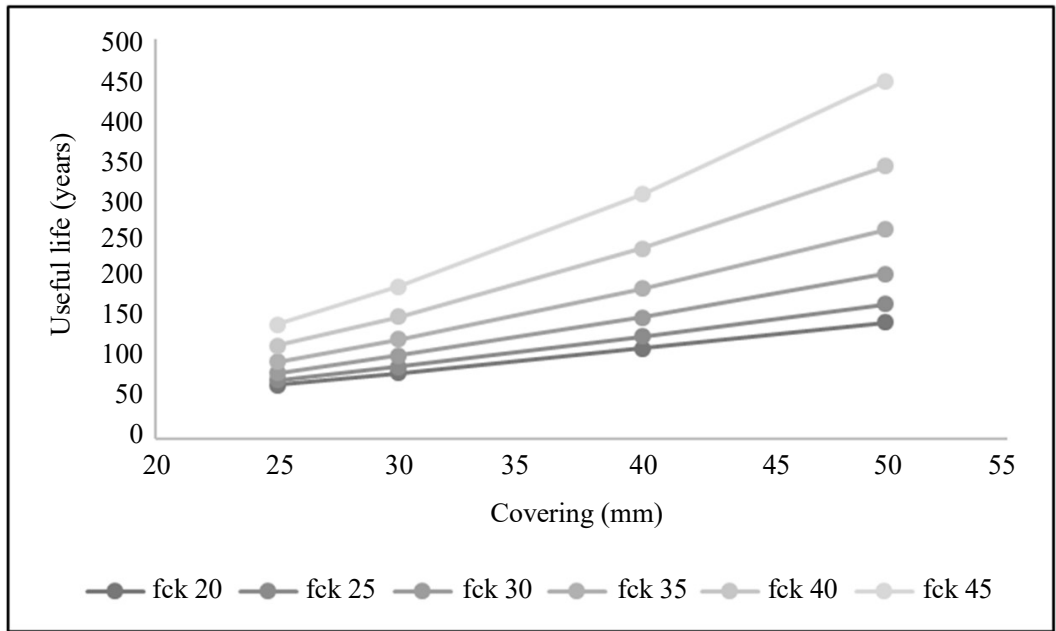

Fig. 4: Influence of strength on the durability of concrete - average humidity

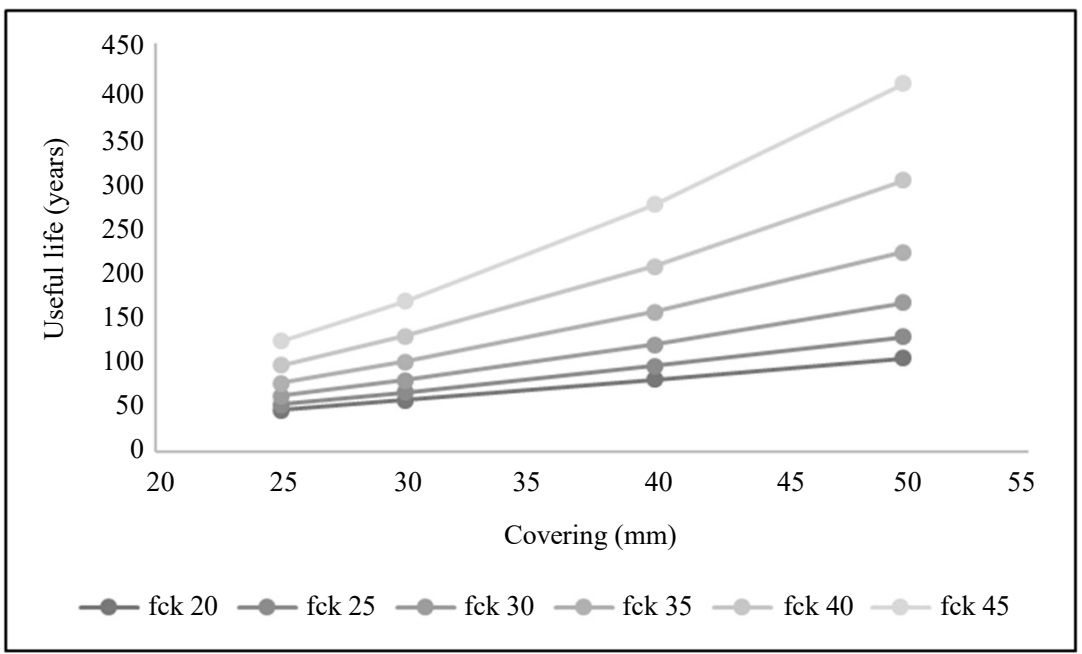

Fig. 5: Influence of fck on the durability of concrete - high humidity

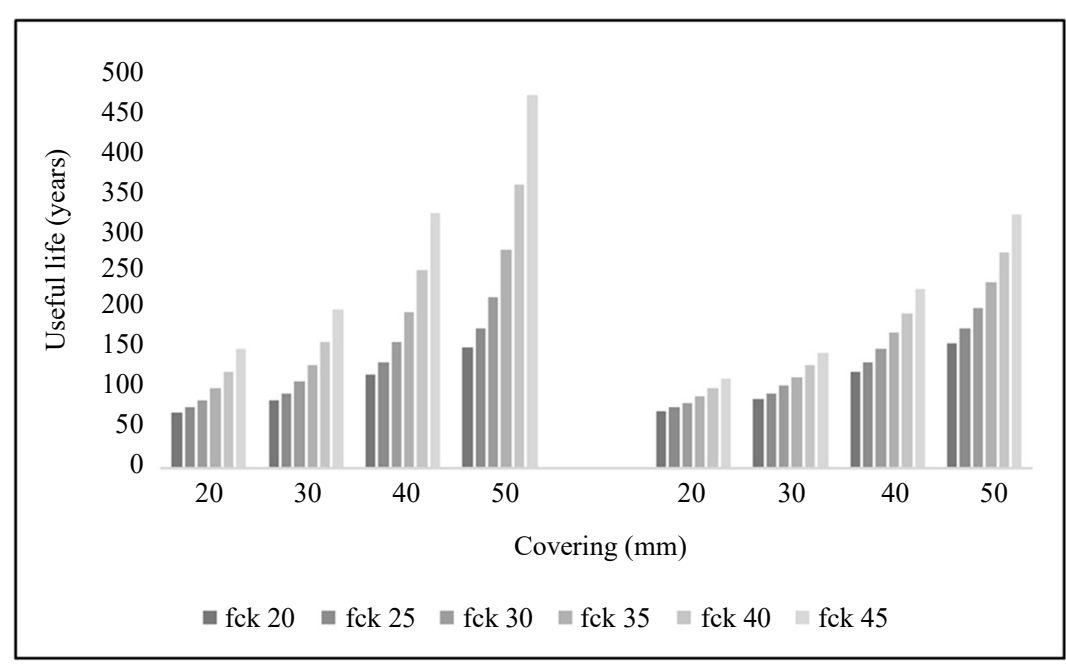

Fig. 6: Comparison between VU - average humidity 


\section{Influence of Cement Type}

Finally, the influence of the addition of pozzolanic material (CPII-Z) in the useful life of the column was investigated. Variations of UL were analyzed as a function of the different values of cover, strength and humidity. The results, illustrated in Fig. 6 to average humidity, are analogous to the previous ones.

As observed from Fig. 6, to concrete strengths of up to $25 \mathrm{MPa}, \mathrm{CPII}-\mathrm{Z}$ cement adds greater or equal durability. For higher concrete strengths CPII-E cement results in a higher useful life. Both types of cement have in their composition additions that provide less porosity to the concrete, a factor that hinders the penetration of aggressive agents. On the other hand, these additions accelerate the carbonation process because they contain high levels of calcium hydroxide. This explains the difference in useful life between types of cement once CP II-E cement has a lower calcium hydroxide content than CP II-Z cement.

\section{Conclusion and Final Considerations}

The present study determined the useful life of optimized reinforced concrete structures, aiming to identify parameters that have a great influence on costs. Among these parameters are the thickness of the covering and the compressive strength of the concrete. Among these parameters, the covering thickness has proved to be very efficient in maximizing the useful life. When comparing the differences in section durability, it was observed that an increase in the covering of $10 \mathrm{~mm}$ generates an increase of useful life of $36 \%$ on average. It was also concluded that increasing the thickness of the cover does not cause a significant influence on the cost of the structure. Regarding the compressive strength of concrete, it was observed that by increasing the strength by $5 \mathrm{MPa}$, the durability increases on average by $38 \%$. Also, as the compressive strength of the concrete increases, the cost of the section decreases. Besides concrete strength and covering, humidity has a significant impact on useful life, with columns subjected to high humidity presenting an average reduction of $22 \%$ in their durability.

Still based on the results of the present study, it was concluded that the useful life is a parameter of great sensitivity. By varying the coverage slightly, the service life increases significantly. Similar behavior was observed to the variation in compressive strength. To strengths above $35 \mathrm{MPa}$, the durability of the section becomes very high, justifying the use of higher strengths for economic purposes. Besides, it was noted that based on certain combinations of type of cement, resistance to compression and covering, a service life much higher than the prescript by design codes was obtained.
In sum, it was concluded that the performance of a concrete structure related to its service life is strongly influenced by covering and concrete strength. The types of cement studied did not cause significant variations in the results. The influence of the diameter of steel bars was not considered in the present study.

\section{Acknowledgment}

The second author is grateful for the financial support received from the Brazilian government in the form of $\mathrm{CNPq}$ grant.

\section{Authors Contributions}

Moacir Kripka: Conceptualization and methodology, software development, writing review.

Tamires L. Mezzomo: Conceptualization and methodology, numerical simulations, original draft preparation.

\section{Ethics}

This article is original and contains unpublished material. The corresponding author confirms that all authors have read and approved the manuscript and no ethical issues involved with declaration of no conflict of interest.

\section{References}

Alexander, M., \& Beushausen, H. (2019). Durability, service life prediction and modelling for reinforced concrete structures-review and critique. Cement and Concrete Research, 122, 17-29. https://doi.org/10.1016/j.cemconres.2019.04.018

ABNT. (2014). NBR 6118: Design of concrete structures Procedure. Brazilian Association of Technical Standards, Rio de Janeiro, Brazil.

Bordignon, R., \& Kripka, M. (2012). Optimum design of reinforced concrete columns subjected to uniaxial flexural compression. Computers and Concrete, 9(5), 327-340. https://doi.org/10.12989/cac.2012.9.5.327

Bueno, G. M., Carneiro, E. R., Ramão, A. C. L., Piva, G. O., \& Tutikian, B. F. (2019). Evaluation of reinforced concrete structural durability in the post-occupation phase-A case study in Novo Hamburgo/RS. REMInternational Engineering Journal, 72(1), 9-16. https://doi.org/10.1590/0370-44672018720040

Cao, J., Liu, L., \& Zhao, S. (2020). Relationship between Corrosion of Reinforcement and Surface Cracking Width in Concrete. Advances in Civil Engineering, 2020, 1-4. https://doi.org/10.1155/2020/7936861 
Clear, K. C., \& Hay, R. E. (1973). Time-to-corrosion of reinforcing steel in concrete slabs vol 1. Effect of mix design and construction parameters. Washington: Federal Highway Administration. https://trid.trb.org/view/94636

Dede, T., Kripka, M., Togan, V., Yepes, V., \& Rao, R. V. (2019). Usage of optimization techniques in civil engineering during the last two decades. Current Trends in Civil \& Structural Engineering, 1(1), 1-17. https://doi.org/10.33552/CTCSE.2019.02.000529

Fomento, M. (2008). Code on Structural Concrete EHE-08. Ministry of Promotion. Madrid, Spain.

Gardner, D., Lark, R., Jefferson, T., \& Davies, R. (2018). A survey on problems encountered in current concrete construction and the potential benefits of self-healing cementitious materials. Case Studies in Construction Materials, 8, 238-247. https://doi.org/10.1016/j.cscm.2018.02.002

Joukoski, A., Portella, K. F., Baron, O., Garcia, C. M., Vergés, G. R., Sales, A., \& De Paula, J. F. (2004). The influence of cement type and admixture on life span of reinforced concrete utility poles subjected to the high salinity environment of Northeastern Brazil, studied by corrosion potential testing. Cerâmica, 50(313), 12-20. https://doi.org/10.1590/S0366-69132004000100003

Kim, J., Kitagaki, R., \& Choi, H. (2020). Pore Filling Effect of Forced Carbonation Reactions Using Carbon Dioxide Nanobubbles. Materials, 13(19), 4343. https://doi.org/10.3390/ma13194343

Kirkpatrick, S., Gelatt, C. D., \& Vecchi, M. P. (1983). Optimization by simulated annealing. Science, 220(4598), 671-680.

https://doi.org/10.1126/science.220.4598.671 de Medeiros, G. F., \& Kripka, M. (2014). Optimization of reinforced concrete columns according to different environmental impact assessment parameters. Engineering Structures, 59, 185-194. https://doi.org/10.1016/j.engstruct.2013.10.045

Possan, E., Felix, E. F., \& Thomaz, W. A. (2016). CO 2 uptake by carbonation of concrete during life cycle of building structures. Journal of Building Pathology and Rehabilitation, 1(1), 1-9. https://doi.org/10.1007/s41024-016-0010-9

Rao, N. V., \& Meena, T. (2017, November). A review on carbonation study in concrete. In IOP Conference Series: Materials Science and Engineering, 263, 032011. https://doi.org/10.1088/1757-899X/263/3/032011

Santos, B., Albuquerque, D., \& Ribeiro, D. (2020). Effect of the addition of metakaolin on the carbonation of Portland cement concretes. Revista IBRACON de Estruturas e Materiais, 13(1), 1-18. https://doi.org/10.1590/s1983-41952020000100002

Tutti, K. (1982). Corrosion of Steel in Concrete. Swedish Cement and Concrete Research Institute. Stockholm, Suecis.

Van Mullem, T., Gruyaert, E., Caspeele, R., \& De Belie, N. (2020). First large scale application with selfhealing concrete in belgium: analysis of the laboratory control tests. Materials, 13(4), 997. https://doi.org/10.3390/ma13040997 